\title{
Peer Punishment with Third-Party Approval in a Social Dilemma Game
}

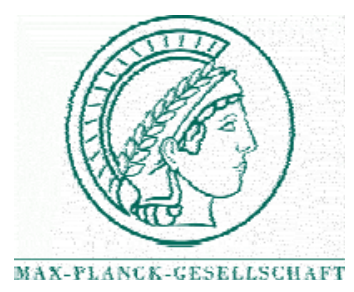

Max Planck Institute for

Tax Law and Public Finance

Department of Public Economics

http://www.tax.mpg.de 
Working papers of the Max Planck Institute for Tax Law and Public Finance Research Paper Series serve to disseminate the research results of work in progress prior to publication to encourage the exchange of ideas and academic debate. Inclusion of a paper in the Research Paper Series does not constitute publication and should not limit publication in any other venue. The working papers published by the Max Planck Institute for Tax Law and Public Finance represent the views of the respective author(s) and not of the Institute as a whole. Copyright remains with the author(s).

Max Planck Institute for Tax Law and Public Finance

Marstallplatz 1

D-80539 Munich

Tel: $\quad+498924246-0$

Fax: $\quad+498924246-501$

E-mail: ssrn@tax.mpg.de

http://www.tax.mpg.de 


\title{
Peer Punishment with Third-Party Approval in a Social Dilemma Game
}

\author{
Fangfang $\operatorname{Tan}^{1}$ and Erte Xiao ${ }^{2}$
}

\begin{abstract}
This paper investigates how punishment promotes cooperation when the punishment enforcer is independent of its proposer. In a prisoner's dilemma experiment, compared with the case when the implicated parties are allowed to punish each other, cooperation is lower when the enforcement of punishment requires approval from an independent third party. Our data show that the independent third party mitigates the severity of punishment and consequently diminishes the effectiveness of punishment on promoting cooperation when antisocial punishment proposals are rare.
\end{abstract}

\section{Keywords}

Social dilemmas, third party, punishment, cooperation, experiment

\section{JEL classification}

C72, C92, D63

\footnotetext{
${ }^{1}$ Department of Public Economics, Max Planck Institute for Tax Law and Public Finance, Marstallplatz 1, D-80539, Munich, Germany, fangfang.tan@tax.mpg.de. Tel: + 49-89-24246-5252, Fax: + 49-89-24246-5299.

${ }^{2}$ Corresponding author. Department of Social and Decision Sciences, Carnegie Mellon University, 208 Porter Hall, Pittsburgh, PA, 15213, exiao@andrew.cmu.edu. Tel: +1-412-268-6780 ; Fax: +1-412-268-6938.
} 


\section{Introduction}

Punishment is a common means to enforce cooperation in a society. Numerous laboratory studies have shown that cooperation can sustain even among strangers under peer punishment mechanisms where the implicated parties can propose and enforce punishment on defectors (e.g., Fehr and Gächter, 2000; Masclet et al., 2003; Falk et al., 2005). In many naturally occurring environments, however, an independent third party decides whether or how to enforce sanctions proposed by the implicated parties. For example, tribe leaders or organization managers often have to decide whether to implement sanctions requested by the community or organization members. In this paper we take a first step toward understanding how sanctions promote cooperation when enforcers are independent of punishment proposers.

Previous studies show that individuals are often willing to impose costly punishment on defectors in view of the long-term benefit of building a cooperative relationship (Gürerk et al., 2006; Gächter et al., 2008). In addition, negative emotions trigger costly punishment on wrongdoers even when there is no monetary benefit from doing so (Sanfey et al., 2003; Xiao and Houser, 2005; Hopfensitz and Reuben, 2009). However, emotions experienced by the punishment receivers, such as vengeance or spite, also lead to antisocial punishment (i.e., to punish cooperators).

Based on these previous findings, we construct two hypotheses surrounding the decisions of an independent third party who is empowered with the right to uphold or negate proposals for punishment. On the one hand, a third party, as an outsider, is more likely to veto antisocial punishments (Hypothesis 1) as his judgment is less likely to be influenced by vengeance and more likely to be consistent with the existing social norms (Cubitt et al. 2011; Fehr and Fischbacher, 2004; Xiao, 2010). Indeed, previous studies on antisocial punishment argue for the importance of "shunning retaliation and centralizing punishment in the hands of the state" (Herrmann et al., 2008). On the other hand, a third party who is not in the position of the victims and who does not benefit from long-term cooperation may reject imposing costly punishment on the defectors (Hypothesis 2) for reasons such as short-run efficiency. Croson and Konow (2009) also find that impartial spectators punish less than implicated stakeholders due to the difference in their moral judgment.

Antisocial punishment has been shown to have a detrimental effect on cooperation, but punishment toward defectors can promote cooperation (see, e.g., Ertan, et al., 2009; Falk et al., 2005; Herrmann et al. 2008; Masclet et al., 2003; Nikiforakis, 2008; Xiao and Kunreuther, 2011). Thus, our hypotheses imply that the intervention of a third party is a double-edged sword: It promotes cooperation if antisocial punishment is pervasive, but it reduces cooperation when antisocial punishment is rare.

To test our hypotheses, we design an experiment based on a finitely repeated prisoner's dilemma game. In the baseline, players can directly impose costly punishment after observing each other's actions. In the target treatment, players make punishment proposals to an independent third party. Punishment will be implemented at the proposer's cost if the third party approves it. 
We find the cooperation rate is significantly lower in the target treatment than the baseline. Supporting our hypotheses, the data show that third parties reject both antisocial punishment and punishment towards defectors. As antisocial punishment is rare in our experiment, the intervention of the third-party enforcer diminishes the effectiveness of peer punishment.

\section{Experiment}

Our experiment consists of two treatments: baseline and third-party approval (TPA). Subjects are randomly assigned to a group of three. Each interacts with the same group in the same role (A, B, or $\mathrm{C}$ ) for 20 periods.

In the first stage of each period, $\mathrm{A}$ and $\mathrm{B}$ decide simultaneously whether to cooperate (Option I) or defect (Option II) in a prisoner's dilemma game (see Table 1). The decision results in a payoff, in which the exchange rate is 40 tokens to 1 euro.

Table 1: Payoff table of the prisoner's dilemma game

Person B

\begin{tabular}{llrr|rr|} 
& \multicolumn{2}{c}{ Option I } & \multicolumn{2}{c}{ Option II } \\
\cline { 3 - 6 } & Option I & 30 & 30 & 15 & 40 \\
\cline { 3 - 6 } & Option II & 40 & 15 & 20 & 20 \\
\hline
\end{tabular}

In the second stage, upon observing each other's choices, A and B simultaneously and independently select how many tokens to deduct from the other player. Every three tokens deducted from the other player costs a player one token. The deduction amount does not go to any player's earnings.

In the Baseline, $\mathrm{C}$ is merely an observer of the experiment. In the TPA treatment, $\mathrm{C}$ must decide whether to veto the punishment decisions proposed by $\mathrm{A}$ or $\mathrm{B}$, if any. Punishment proposals are implemented upon C's approval. ${ }^{3}$ The punishment proposers do not incur any cost if the proposed punishment is not approved.

In both treatments, all the decisions are revealed to each player at the end of each period. To keep the information symmetry between treatments, A and B still can see each other's punishment proposals in the TPA treatment even if $\mathrm{C}$ bans any of them.

C's earnings in both treatments are independent of the outcome of the game. The program randomly draws a number from the prisoner's dilemma payoff matrix (15, 20, 30, 40) with an equal probability, and this is common knowledge. Moreover, C learns his own earnings only at the end of the experiment, while A and B never know

\footnotetext{
${ }^{3}$ In naturally occurring environments, institutions can empower the third party in various ways. For example, the third party can have the right to revise the punishment. As a first step, we adopt a binary decision mechanism to understand the impact of the third party's intervention. We find the cooperation rate is lower under the third party's intervention because the punishment is less severe. It is possible that the cooperation rate could be higher if the third party could revise the proposed punishment amount. In our experiment, we do not observe any evidence that the third party's decisions vary on the proposed punishment amount. For example, punishment proposals on defectors lower than 6 tokens are approved in 57 out of 107 cases (53.3\%) and those higher than 6 tokens are approved in 118 out of 184 cases (64.1\%). The correlation between approval rate and proposed punishment amount is not statistically significant. This implies that even allowing the third party to revise the proposal may not promote cooperation in our setting. Further studies are needed to understand how different ways of empowering the third party influence the outcome.
} 
the actual earnings of C. This setting minimizes the possibilities that players' decisions are affected by the comparison of earnings between the third party $C$ and the players $\mathrm{A}$ and $\mathrm{B}$.

We conducted our experiment at the CentER lab at Tilburg University. We recruited 37 independent groups for the baseline treatment and 38 groups for the TPA treatment (225 subjects in total). The experiment was programmed and conducted in z-Tree (Fischbacher, 2007). Each period counted toward final earnings, resulting in average earnings of $€ 12.90$ per person.

\section{Results}

Figure 1 plots the dynamics of the average group cooperation rates in both treatments. We find that the average cooperation rate is significantly lower in the TPA treatment than the baseline $(0.47$ vs. 0.70 , Mann-Whitney test, $\mathrm{p}<0.05){ }^{4}$ Furthermore, the average earnings are also marginally significantly lower in the TPA treatment (23.52 vs. 25.30, $\mathrm{p}<0.10)$.

Figure 1. Average cooperation rates over 20 periods by treatment

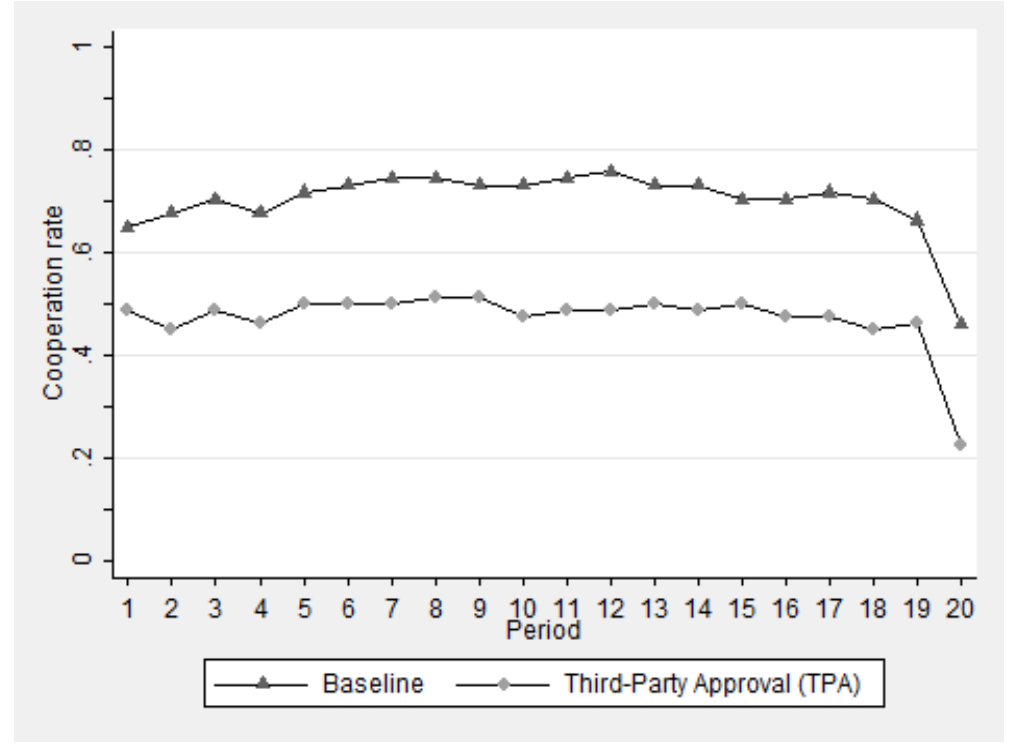

To understand the observed treatment effect on cooperation, we test our hypotheses by comparing the punishment decisions across treatments. Given that punishment severity is determined by both the frequency and the amount, we report the expected proposed and enforced punishment amount to the cooperators and defectors across treatments in Figure 2.

We find supporting evidence for Hypothesis 1 that third parties reject antisocial punishment. As shown in Figure 2, in the TPA treatment, third parties significantly reduce the implementation of antisocial punishment proposals (1.90 vs. 0.91, p < 0.05). The data also support Hypothesis 2 that third parties lower punishment on defectors $(6.13$ vs. $3.75, \mathrm{p}<0.1)$. Moreover, our data suggest an indirect effect of

\footnotetext{
${ }^{4}$ All tests reported in this paper are two-sided Mann-Whitney rank-sum test. In all the analysis, we treat each group as an independent observation.
} 
third parties' interventions on the punishment proposals especially for the defectors, which may also contribute to the low cooperation level in the TPA treatment. Compared to the baseline, As and Bs propose much less punishment for defectors in the TPA treatment although the difference is not statistically significant (6.13 vs. 14.94, $\mathrm{p}=0.13$ ). The proposed antisocial punishment remains very low in the TPA treatment as in the baseline, although it is marginally significantly higher than the baseline (1.90 vs. 1.07, $\mathrm{p}<0.1$ ).

Consistent with previous studies, our data suggest that antisocial punishment decreases cooperation while punishment imposed on defectors increases cooperation. In both treatments, cooperators, if not punished, continue cooperating in about $90 \%$ of the cases in the next period. In contrast, if punished, cooperators in both treatments continue cooperating in less than 50\% cases. Defectors, if not punished, continued cooperating in less than $10 \%$ of the cases in both treatments in the next period. But when defectors are punished, they switch to cooperation in $22.58 \%$ of the cases in the baseline and 35\% of the cases in the TPA treatment.

As we discussed above, our hypotheses indicate that the overall effect of the third party's intervention is determined by how often antisocial punishments occur. In our experiment, antisocial punishment occurred only in a few cases. In particular, cooperators are punished in 17 out of 1036 cases (1.64\%) whereas defectors are punished in 80 out of 444 cases (18.02\%) in the baseline. In the TPA treatment, cooperators are proposed to be punished 54 out of 716 cases $(7.54 \%)$ whereas defectors are proposed to be punished 291 out of 804 cases (36.19\%). As a result, the third party's intervention leads to a lower cooperation rate because it largely decreases the positive impact of punishment on defectors.

Figure 2. Expected punishment amount by treatment

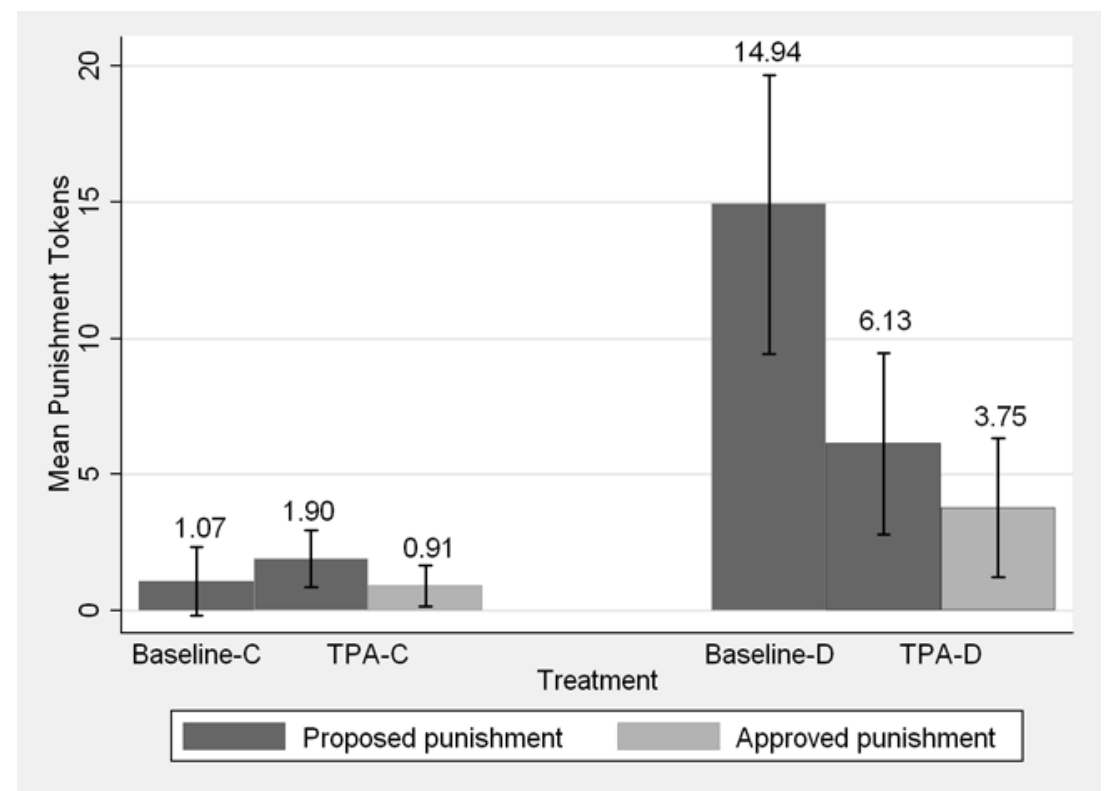

Notes: For each group in each treatment, we calculate the product of the average punishment amount towards cooperators (defectors) and the frequencies of punishment decisions to cooperators (defectors). The expected punishment amount is the average of these products. Baseline-C represents antisocial punishment to cooperators in baseline; TPA-C represents antisocial punishment to cooperators in TPA; Baseline-D means punishment to 
defectors in baseline; TPA-D means punishment to defectors in TPA. In the baseline, the proposed punishment is also the approved punishment.

\section{Conclusion}

Our experiment data suggest that the intervention of independent punishment enforcers diminishes punishment both for cooperators and defectors. One implication is that when the antisocial punishment is not pervasive, the intervention of a third party reduces the effectiveness of the peer punishment mechanism in promoting cooperation.

Our study offers the first evidence that third-party intervention could lower cooperation in social dilemmas although it meanwhile controls antisocial punishment. As a first step, we exclude many features of the punishment mechanism with third-party approval in the naturally occurring environment. For example, we randomly assign a subject to be a third party in the experiment. In reality, the right to be the enforcer is either decided by law (such as judges) or elected by the governed people (such as tribe leaders). Moreover, a third party often benefits from good reputation and cooperation among the involved parties. Nevertheless, our findings draw attention to the importance of studying how these features influence effective punishment institutions when an independent third party is empowered with the right to uphold or negate punishment.

\section{Acknowledgement}

We thank Daniel Houser, Martin Kocher, Wieland Müller, Charles Noussair, Jan Potters, and Arno Riedl, as well as participants at the Carnegie Mellon University, Tiber work-in-progress seminar, M-BEES 2011 conference, the 10th Tiber Symposium on Psychology and Economics, and the 2011 ESA European conference in Luxembourg for valuable comments. We gratefully acknowledge the financial support from CentER lab funding at Tilburg University. Maolong $\mathrm{Xu}$ and Bastian Henze provided excellent assistance for the experimental sessions.

\section{References}

Croson, R., Konow, J. 2009. Social preferences and moral biases, Journal of Economic Behavior \& Organization 69 (3), pp 201-212.

Cubitt, R. P., Drouvelis, M., Gächter, S., Kabalin, R. 2011. Moral judgments in social dilemmas: How bad is free riding? Journal of Public Economics 95, pp253-264.

Ertan, A., Page, T., Putterman, L. 2009. Who to punish? Individual decisions and majority rule in mitigating the free rider problem. European Economic Review 53, 495-511.

Falk, A., Fehr, E., Fischbacher, U. 2005. Driving forces behind informal sanctions. Econometrica 73, pp2017-2030.

Fehr, E., Fischbacher. U. 2004. Third-party punishment and social norms. Evolution and Human Behavior 25(2), pp63-87.

Fehr, E., Gächter, S. 2000. Cooperation and punishment in public goods experiments. American Economic Review 90(4), pp980-994. 
Fischbacher, U. 2007. z-Tree: Zurich toolbox for ready-made economic experiments. Experimental Economics 10(2), pp171-178.

Gächter, S., Renner, E., Sefton, M. 2008. The long-run benefits of punishment. Science 322, pp1510.

Gürerk, Ö, Irlenbusch, B., Rockenbach, B. 2006. The competitive advantage of sanctioning institutions. Science 312 (5770), pp108-111.

Herrmann, B., Thoni, C., Gächter, S. 2008. Antisocial punishment across societies. Science 319(5868), pp1362-1367.

Hopfensitz, A., Reuben, E. 2009. The importance of emotions for the effectiveness of social punishment. The Economic Journal 119(540), pp1534-1559.

Masclet, D., Noussair, C., Tucker, S. and Villeval, M. C. 2003. Monetary and non-monetary punishment in the voluntary contributions mechanism. American Economic Review 93, pp366-380.

Nikiforakis, N., 2008. Punishment and counter-punishment in public good games: Can we really govern ourselves? Journal of Public Economics 92(1-2), pp91-112.

Sanfey, A., Rilling, J., Aronson, J.A., Nystrom, L., Cohen, J.D. 2003. The neural basis of economic decision-making in the ultimatum game. Science 13(5626), pp1755-1758.

Xiao, E. 2010. Profit seeking punishment corrupts norm obedience, SSRN working paper.

Xiao, E. and Houser, D. 2005. Emotion expression in human punishment behavior. Proceedings of the National Academy of Sciences 102 (20), pp7398-7401.

Xiao, E. and Kunreuther, H. 2011. Punishment and cooperation in stochastic prisoner's dilemma game, mimeo. 


\section{Appendix}

\section{Experiment Instructions (TPA Treatment)}

Thank you for coming to the experiment. Please read these instructions carefully! Talking is not allowed at any time during this experiment. If you have a question, please raise your hand, and an experimenter will assist you.

This experiment consists of 20 periods. Each participant is in the role of either Person A, or Person B, or Person C. Each participant's role will be randomly determined by the computer at the beginning of the experiment and remain the same during the experiment. The computer will also randomly group a Person A with a Person B and a Person $\mathrm{C}$ at the beginning of the experiment. Each participant will stay in the same group during the whole experiment (i.e. 20 periods).

Each period consists of two stages as described below:

\section{Stage 1:}

Person A and Person B will simultaneously and individually decide whether to choose “Option I” or “Option II”. Each one’s earnings are determined as follows: (a) if both Person A and Person B select Option I, each earns 30 tokens; (b) if both Person A and Person B select Option II, each earns 20 tokens; and (c) if one selects Option I and the other one selects Option II, the one who chooses Option I earns 15 tokens and the one who chooses Option II earns 40 tokens. The payoff table below lists all the possible payoff outcomes for each possible scenario. The number on the left in each cell is Person A's payoff and the number on the right is Person B's payoff.

\section{Payoff Table}

Person B

\begin{tabular}{llrr|rr|} 
& \multicolumn{2}{c}{ Option I } & \multicolumn{2}{c}{ Option II } \\
\cline { 3 - 6 } Person A & Option I & 30 & 30 & 15 & 40 \\
\cline { 3 - 6 } & Option II & 40 & 15 & 20 & 20 \\
\hline
\end{tabular}

Person C's earnings in each period is determined by a random process. The computer will randomly assign $30,15,40$ or 20 , with equal chance, as Person C's earnings in the first stage of each period. Person $\mathrm{C}$ will not know this randomly assigned payoff amount until the end of the experiment. Neither Person A nor Person B will ever 
know Person C’s randomly payoff throughout or after the experiment.

\section{Stage 2}

At the beginning of the second stage, all participants of a group will be informed of the decisions and earnings of the Person A and the Person B of the group. Again, Person C's earnings will not be revealed to anyone including Person C him/herself.

First, Person A will have an opportunity to individually propose to the Person $C$ in his/her group whether to deduct any amount of tokens from the matched Person B's payoff. Every three tokens deducted from Person B's payoff, if approved by Person C (see details below), will cost Person A one token. Meanwhile, Person B will also have the same opportunity to propose to Person $C$ whether to deduct any amount of tokens from the matched Person A's payoff. Similarly, every three tokens deducted from Person A's payoff, if approved by Person C, will cost Person B one token.

The maximum deduction amount a person can impose on the other is 40 tokens. That is, you can propose to deduct from the other person's payoff by any amount of tokens between 0 and 40 . However, the amount should be an integer number (e.g. 0, 1, 2...).

Next, Person C will see both Person A's and Person B's decisions and payoffs in the first stage, and also Person A's and Person B's proposals in the second stage.

- If either Person A or Person B proposed any deduction for the matched Person B or Person A, then Person $C$ will have to decide whether to approve the proposal(s). If Person $\mathrm{C}$ decides to approve the proposed deduction amount, then the deduction will be implemented. In this case, the proposer's earnings will also be deducted by one-third of the deduction amount as we noted above. Person C's payoff will not change no matter what decision he/she makes. (Note: Person C does not know his/her randomly assigned payoff in the first stage when making this decision).

- If neither Person A nor Person B proposed any deduction, then Person C does not have any decision to make. No change will be made for any one's earnings.

At the end of each period, each participant will see the decisions of each one in his/her group, the final earnings of Person A and B in that period. 
Each period will proceed in the same way. Each participant will play 20 periods with the same participants. Your final earnings are the sum of your earnings over 20 periods. After all the 20 periods finished, each participant will receive a cash payment in private. The exchange rate of tokens to Euro is:

\section{0 tokens $=1$ Euro}

\section{Examples}

Below are some examples to illustrate how payoffs in each period are determined.

Suppose, in one period, in the first stage, Person A chose Option I and Person B chose Option II. Thus, Person A earns 15 tokens and Person B earns 40 tokens in the first stage. Suppose, in the second stage, Person A proposed to deduct 9 tokens from Person B's earnings and Person B proposed to deduct 6 tokens from Person A's earnings. Also, suppose the computer randomly assigns 30 tokens as Person C's earnings in that period.

- If Person C approved Person A’s proposal but rejected Person B's proposal, each one's earnings in this period are as follows:

Person A's earnings $=15-3=12$

Person B's earnings $=40-9=31$

Person C's earnings $=30$

- If Person C approved both proposals in the above scenario, then each one's earnings in this period are as follows:

Person A's earnings $=15-3-6=6$

Person B's earnings $=40-2-9=29$

Person C's earnings $=30$

- If Person C rejected both proposals in the above scenario, then no one's earnings would be changed. Each one's earnings in this period are as follows:

Person A's earnings $=15$

Person B's earnings $=40$

Person C's earnings $=30$

Now suppose in the second stage of that period, Person A proposed to deduct 8 tokens from Person B's earnings and Person B did not propose any deduction amount. In this case, Person C only needs to decide whether to approve Person A's proposal.

- If Person C approved it:

Person A's earnings $=15-2.67=12.33$

Person B's earnings $=40-8=32$ 
Person C's earnings $=30$

- If Person $C$ rejected it, then no one's earnings would be changed:

Person A's earnings $=15$

Person B's earnings $=40$

Person C's earnings $=30$

\section{Summary}

To repeat, each participant will play in the same group for 20 periods. Each period consists of two stages. In the first stage, each Person A and Person B will decide whether to choose Option I or Option II which will decide each one's earnings in the first stage. Person C's earnings in a period will be randomly determined by the computer (Person $\mathrm{C}$ will know this amount only at the end of the experiment after all the decisions have been made. Person A and Person B will not be informed about this amount throughout the experiment). In the second stage, after knowing Person A and Person B's decisions in the first stage, Person A (Person B) will decide whether to propose any deduction amount to the paired Person B (Person A). The proposed deduction amount will implemented only if Person C approves it. Person C's earnings will not change no matter whether s/he approves the proposal(s).

Please raise your hand if you have any questions at this moment.

The next several pages outline the procedure of the experiment and the computer screens when Person A, Person B and Person C make their decisions. 
In the first stage, Person A and Person B simultaneously decide which option to choose. Person $\mathrm{C}$ will be waiting.

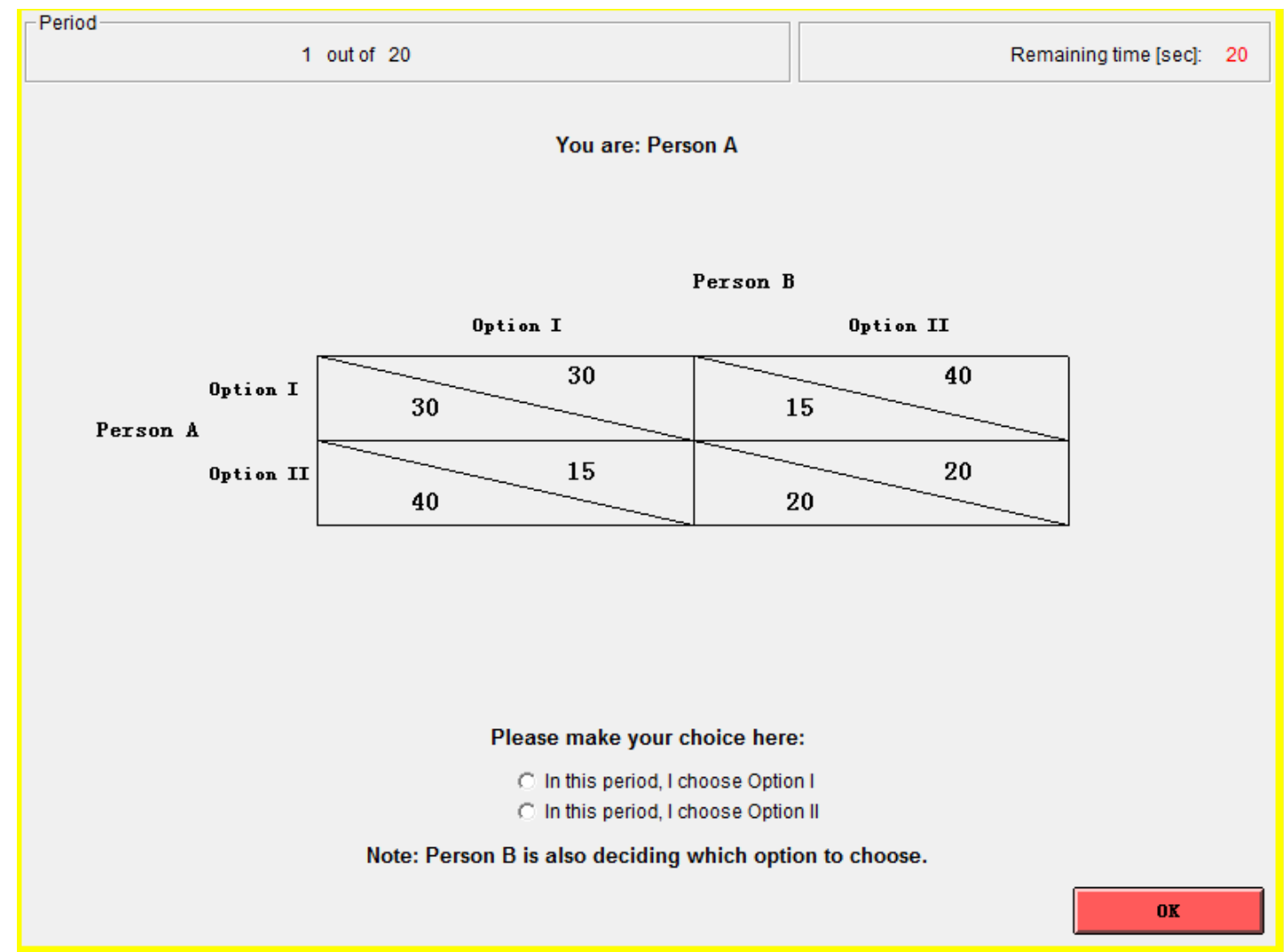


In the second stage, Person A and Person B receive feedback regarding the outcome of the first stage. Then each proposes to the matched Person $C$ whether to deduct any amount of tokens from the matched Person A's or Person B's earnings.

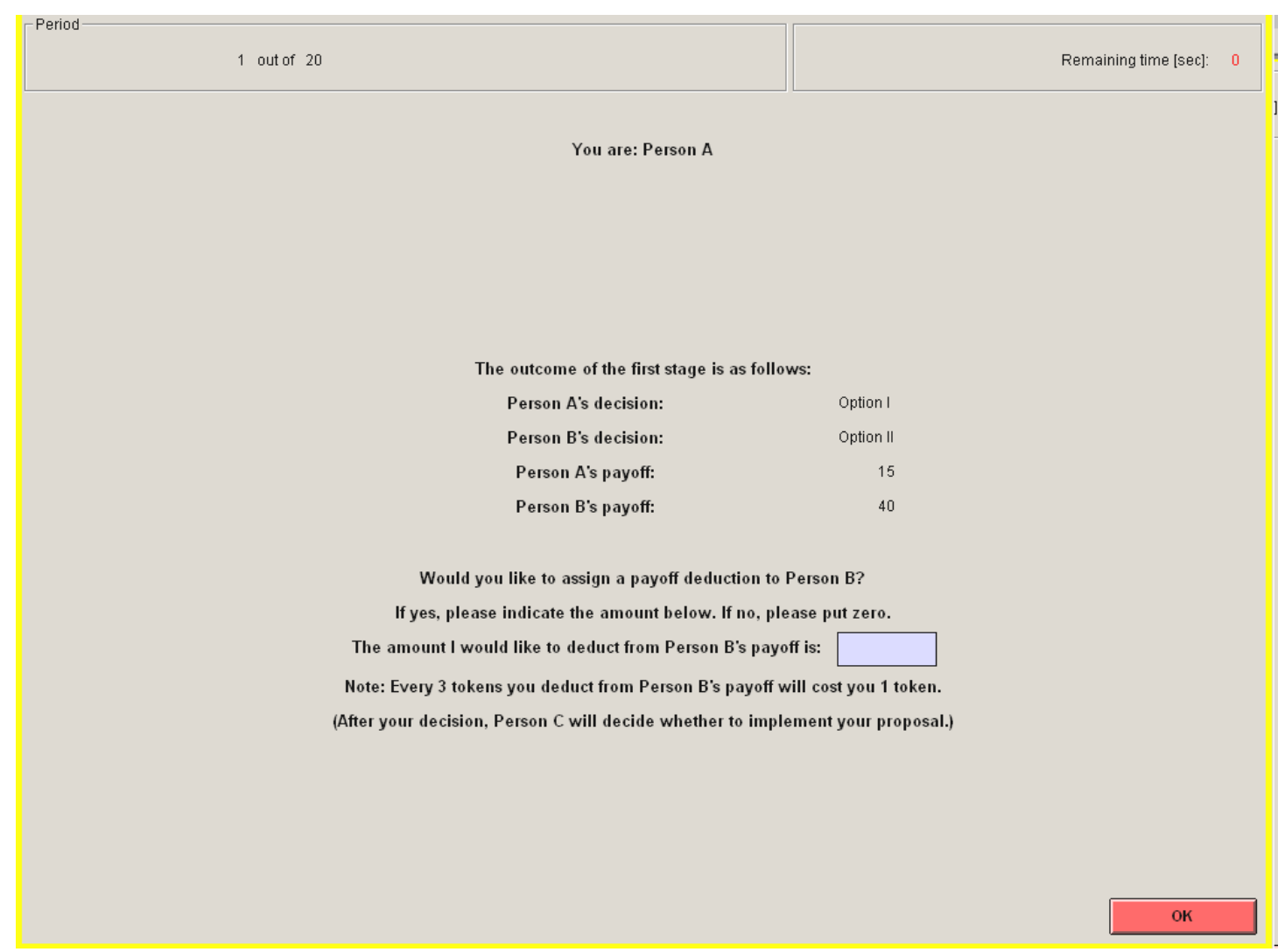


Next, Person C will see both Person A's and Person B's decisions and payoffs in the first stage, and also Person A's and Person B's proposals in the second stage. Then, Person $\mathrm{C}$ decides whether to approve or reject the proposal if any.

Note: Once Person $\mathrm{C}$ clicked the “ $\mathrm{OK}$ ” button, s/he cannot change the decision.

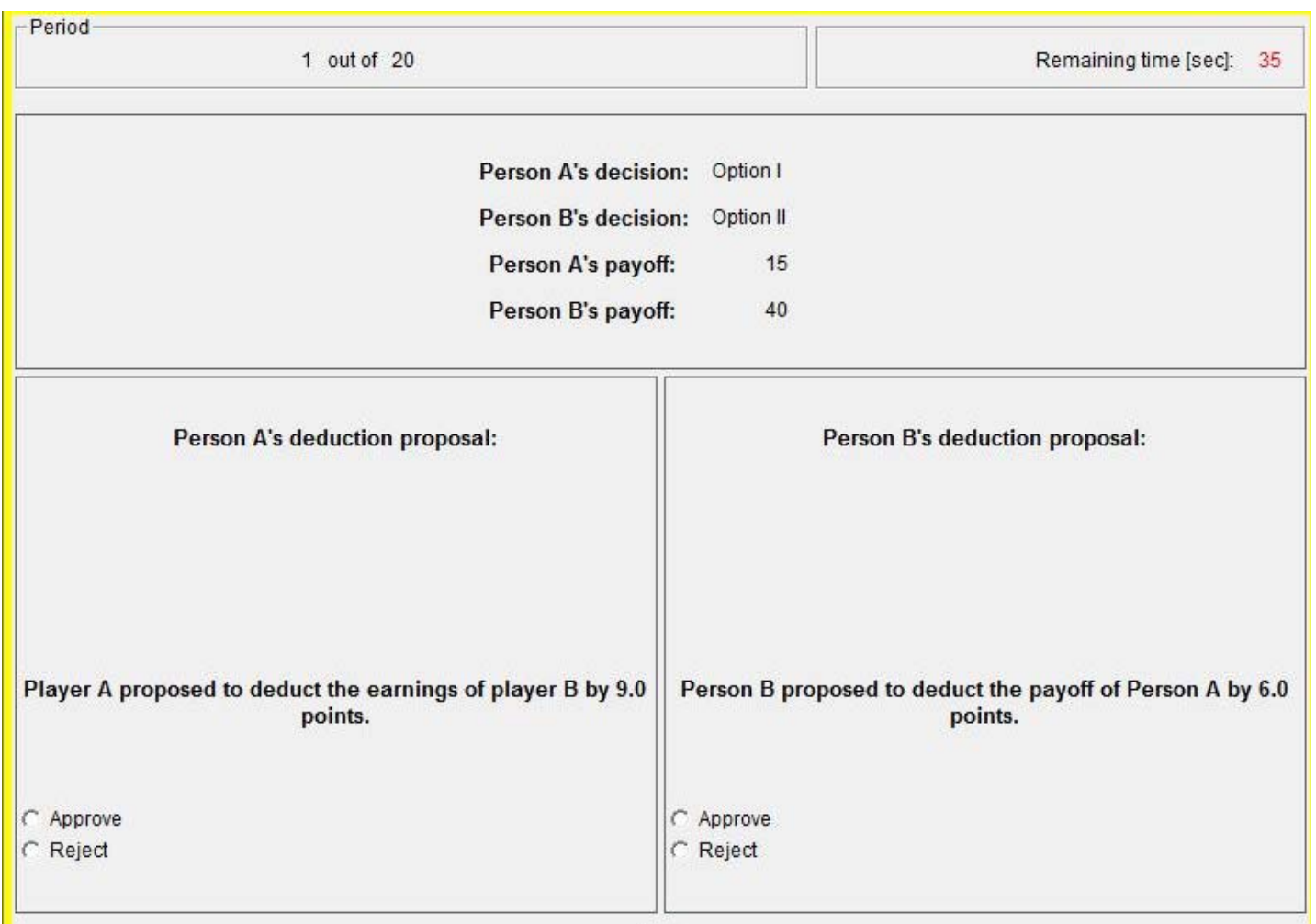


At the end of each period, each participant (Person A, B and C) will see the outcome of that period.

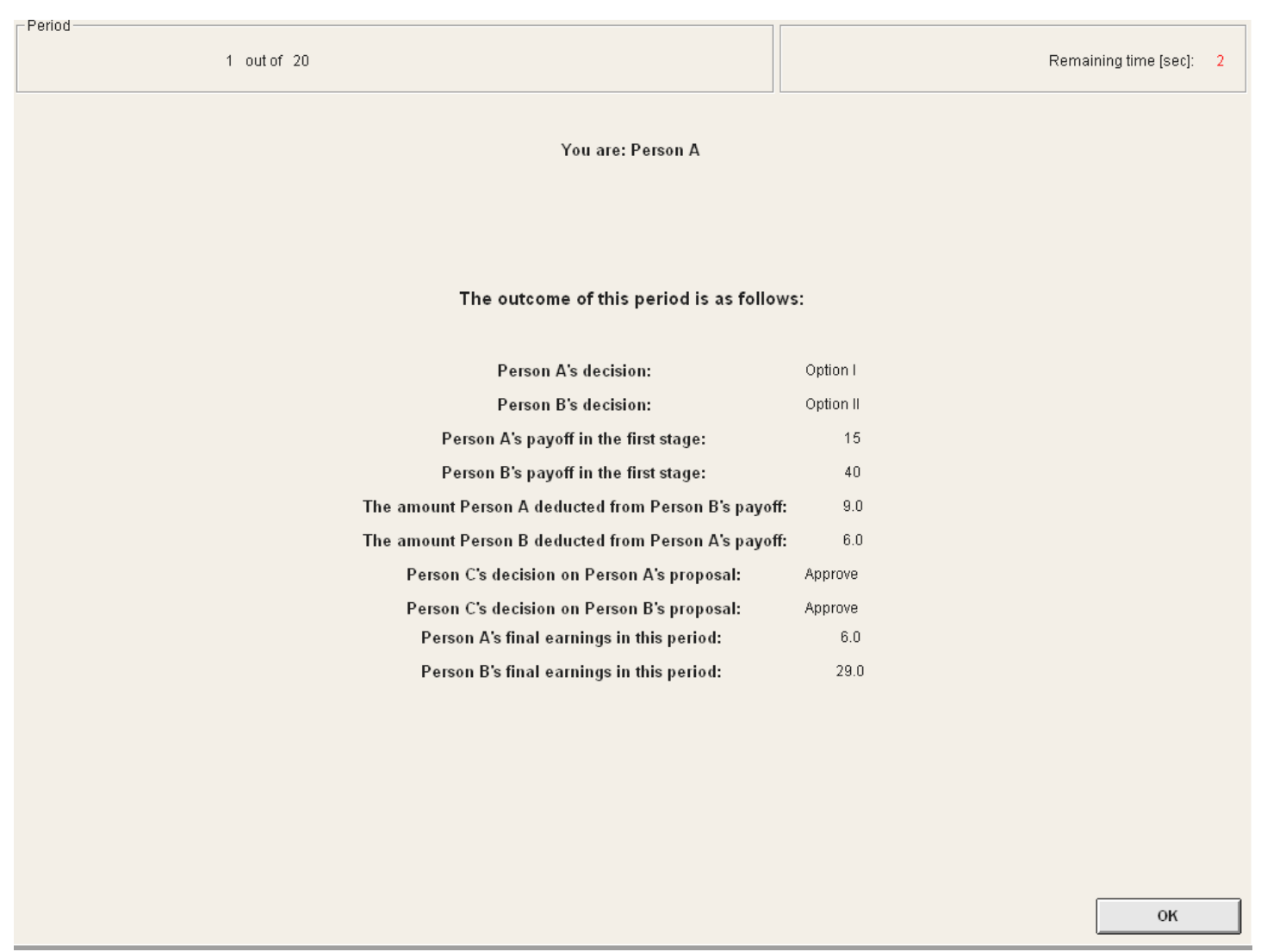

